\title{
Practical Aspects of Laser Holographic Interferometry in Wind Tunnels
}

Joseph P. Licursi and George Lee

September 1985

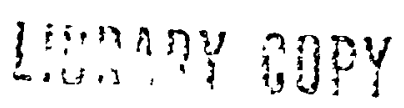

SEP $3019 E ;$

LAIVGLE, PESEARCHCL '

LISTIRY, NA:

"AMPTOR, VIRGIIII 
NASA Technıcal Memorandum 86788

\section{Practical Aspects of Laser Holographic Interferometry in Wind Tunnels}

Joseph P Licursı

George Lee, Ames Research Center, Moffett Field, Calıfornı

September 1985

\section{N/Sก}

National Aeronautics and

Space Admınıstratıon

Ames Research Center

Moffett Field Calıfornia 94035 
Practical aspects of laser holographic interferometry in wind tunnels

Joseph P. Licursi and George Lee

NASA Ames Research Center, MS 227-8, Moffett Field, CA 94035

\section{Abstract}

Practical aspects of using laser holographic interferometry in some NASA Ames wind tunnels are presented. These aspects include the development of techniques for dual-plate interferometry, optics alignment, and laser alignment. In addition, methods to alleviate problems associated with vibration, photographic processing, photographic drying, and photographic reconstruction are discussed.

\section{$\underline{\text { Introduction }}$}

Durıng the past decade, laser holographı interferometry has been demonstrated to be an effective, nonıntrusive tool for measuring density fields in aerodynamic applications. The use of short pulsed laser holography greatly reduces the vibration problems inherent in wind tunnels. A distinct advantage of using holographic interferometry is that high quality optics are not required. Such large scale optical components normally required in wind tunnel flow studies are very costly. The holographic technique is now routinely used for wind tunnel analysis of two-dimensional flows around airfolls 1,2 and more recently, has been applied to three-dimensional fields. 3,4

The bulk of the holographic interferometry literature places emphasis on the aerodynamic aspects rather than the practical aspects of using this technique. This paper presents some practical aspects of using holographic interferometry based on studies conducted at the NASA Ames Research Center. The specialized alignment procedures of the interferometer and lasers are presented and discussed Special photographic processing of the holographic plates, as well as drying and reconstruction methods for dual-plate holography w111 be discussed.

\section{Interferometer}

Off-axis holography is typically used for wind tunnel studies of flow fields. An off-axis interferometer system is shown in Figure 1. The laser beam was split into an object beam and a reference beam. The object beam passed through the test section containing the model and flow field to be measured, while the reference beam passed around the test section Both beams were focused on the holographic recording plate to form a hologram Detalls of off-axis holography can be found in any text book on interferometry. ${ }^{5}$ Pulsed ruby and Nd:Yag lasers are used in wind-tunnel interferometers because the pulse duration is shorter than the high ambient vibration levels present in wind tunnel testing environments. The pulse durations of these lasers are between 15 and 25 nanoseconds.

Several interferometers have been used at Ames Research Center These include both permanent and portable systems. ${ }^{6-8}$ There are three permanent interferometer systems being used at Ames Research Center. These are the Ames $2 \times 2$ Foot Transonic Wind Tunnel interferometer using an Nd:Yag laser as shown in Figure 2, the Army Aeroflightdynamics Directorate Anecholc Test Chamber interferometer using a ruby laser as shown in Figure 3 , and the Ames High Reynolds Number Channel I interferometer also using a ruby laser A portable interferometer usıng an Nd:Yag laser has been used in both the $11 \times 11$ Foot Transonic Wind Tunnel (Figure 4 ), and the $6 \times 6$ Foot Supersonic Wind Tunnel (Figure 5) Note the long beam path lengths (50 to 100 feet) and the numerous optical elements (20 to 30) in these systems, which adversely affect the beam alignment. Other problems affecting these systems include vibration, laser beam wandering, as well as dust particles and temperature fluctuations that are present in all wind tunnels. All these problems adversely affect the performance of these systems and the overall quality of the resulting interferograms.

To illustrate these problems, the $2 \times 2$ Foot Transonic Wind Tunnel interferometer system is used as an example, which is shown in Figure 6 . This system uses a pulsed Nd:Yag laser manufactured by Quanta Ray, Inc. The laser operates at $5300 \AA$ wavelength in the visible green spectrum and has three modes of operation. These modes are single pulse, double pulse, and 10 pulses per second. The laser power output levels were set by adjusting the timing of the Pockels cell trigger This adjustment allowed the laser cavity to fire at different positions on the flash lamp output response curve, shown in Figure 7 This response curve was sensed by a diode detector placed along the beam path and viewed with an oscilloscope. Problems incurred using this interferometer were beam wandering, long beam paths, dust on optical elements, temperature variations, and vibration, all of which adversely affected the optical alignment. Alignment problems also 
increased with additional mirrors and lenses. For example, the reference beam alignment in the $2 \times 2$ foot interferometer system was more critical than the object beam because it contained additional turning mirrors. To facilitate alignment, remotely controlled, motorized actuators were used on those optical mounts that were not readily accessible. To reduce the vibration problem, reinforced mirror mounts were used instead of standard mirror mounts To reduce optical noise in the reference beam, a spatial filter was added at the crossover point of the microscope beam expander just before the hologram recording plate To reduce the amount of dust and minor imperfections in the optical elements appearing on the interferogram, the hologram recording plate was placed slightly in front of the object beam's focus point which defocused the images of the dust and optical imperfections. To reduce temperature variations, optical beams were encased in cloth bellow enclosures to diminish room air currents and the rooms were kept at an ambient temperature.

\section{Alignment}

Laser beam wandering necessitated alignment before each test The following section describes the alignment procedure for the $2 \times 2$ Foot Transonic Wind Tunnel interferometer system. First, the laser was turned on at 10 pulses per second at a low power ( 4 to 5 millijoules) for ten minutes. This brought the laser up to its operating temperature which stabilized it and thus minimized beam wandering. The alignment process was started by adjusting the first mirror through a long focal length lens $(f \ell=1.0 \mathrm{~m}$ ) to steer the unfiltered 6-mm diameter beam into the $150-\mu$ diameter spatial filter pinhole, also shown in Figure 6 . This spatial filter pinhole diameter produced a very smooth beam intensity distribution, making it quite suitable for holography Three micrometers were used to adjust the position of the spatial filter pinhole. When the pinhole was centered on the focal point of the laser beam, a symmetrical diffraction pattern appeared downstream of the pinhole as shown in Figure 8a. The spatial filter pinhole was periodically replaced because the laser beam wandering burned the pinhole edges. This caused an elliptical shaped pinhole which resulted in a distorted defraction pattern as shown in Figure 8b. Holograms taken with noncircular pinholes have nonuniform intensity and produced poor quality interferograms The object and reference beams were then alıgned, separately, along their respective paths to the hologram recording plates. Shutters placed in each beam path near the hologram recording plate allowed one to view and align these beams separately. In the first step of the alignment, the laser was operated at 10 pulses per second This nearly continuous wave beam was easily seen, which facilitated the alignment Each beam was adjusted until a uniform circular pattern was observed on the ground-glass focusing screen of the hologram plate holder. In the second step, to freeze the flow field without using a shutter, the laser was switched from the 10 pulses per second mode to the single pulse mode To check the alignment in this mode, a $4 \times 5$ polaroid-type $55 \mathrm{P} / \mathrm{N}$ film was exposed by a single low-power laser pulse Correctly aligned beams showed an even, grey-colored circular pattern on the polaroid print, as shown in Figure 9a. An uneven grey pattern, as shown in Figure 9b, indicated incorrect alignment It was important to get the proper grey exposure by trial and error adjustment of the laser power, because over or underexposed film masked the even circular pattern required for correct alıgnment. The final step was to check the alignment at maximum laser power ( 40 to $50 \mathrm{millijoules).} \mathrm{This} \mathrm{high} \mathrm{energy}$ level was required for proper holographic plate exposure. A final alignment check at maxımum laser power was made by placing a $4 \times 5-1$ nch sheet of fully exposed and developed Kodak $\operatorname{Tr} 1-X$ film on the ground-glass focusing screen and observing the beam The exposed sheet film attenuated the high intensity of the beam so that it could be viewed through the film to check alignment at high power, in case the laser had drifted.

\section{Hologram recording}

In dual-plate interferometry, ${ }^{9}$ an ambient condition holographic plate was recorded (pre- and post-test) to give the reference density in the wind-tunnel test section. A second holographic plate was recorded at the test conditions Agfa Type-10E56 $4 \times 5$-1nch glass plates were used to record the holograms. These plates, emulsion side facing outward were loaded in total darkness into standard double-sided plate holders. Initially, a numerical identification number was hand scribed on each holographic plate as they were loaded. This laborious procedure was later replaced with a 12-digit LED electronic identification system mounted on the hologram recording plate holder. This identification system pre-exposed a digital code of the test conditions on the unused area of the hologram plate, as shown in Figure 10. Relative position of the test condition and ambient condition holographic plates in the recording plate holder were separated by $5 \mathrm{~mm}$, using a metal spacer. This indicative space was used during reconstruction to separate the test condition and ambient condition holographic plates. Ambient and test condition holographic plates were exposed at maximum laser power of 40 to $50 \mathrm{millijoules} \mathrm{Several} \mathrm{ambient} \mathrm{condition} \mathrm{and} \mathrm{test} \mathrm{condition} \mathrm{holographic} \mathrm{plates} \mathrm{were}$ taken for each test condition because variations in the laser's power output and characteristic mode affected the photographic density of the plates.

\section{Hologram processing}

Holographic plates were developed using a standard black and white processing technique with some modifications. The plates were processed using Kodak $4 \times 5$-1nch metal hangers submerged in one-gallon Kreonite 
type tanks. The solution in the tanks was agitated with nitrogen gas bursts, which was controlled by a timed valve system Nitrogen gas prevented oxidation of the solutions and ensured even development of the plates. The first step was to load the exposed plates in total darkness into the hangers and immerse them in the developer Kodak D-19 developer was diluted with equal parts of water, or used full strength, depending on exposure of the plates Processing time was determined by visual inspection during the developing stage, which normally took a maximum of 4 to 5 minutes at $20^{\circ} \mathrm{C}$. The plates were inspected for exposure density using diffused light reflected from a safelight. The inspection safelight used was a Kodak Model A-15W with a type OC filter and three layers of white bond paper to further reduce the light level. The second step was to quickly immerse the developed plates in Kodak stop bath Type 33 for 60 seconds at $20^{\circ} \mathrm{C}$ to stop plate development. The third step was to immerse these plates in Kodak Ektaflo fixer diluted with water, 7.1 , for 4 minutes at $20^{\circ} \mathrm{C}$ to complete plate fixation. This was followed by washing the plates in running water in the final tank for 15 minutes at $20^{\circ} \mathrm{C}$. The plates were then removed from their hangers and $1 \mathrm{mmersed}$ in a tray containing denatured alcohol at room temperature for 15 seconds to allow evaporation of the water and to minimize uneven plate emulsion shrinkage The plates were then removed from the alcohol bath and 1 mnediately dried in a Kreonite temperature-controlled drying cabinet using filtered air. Another method was to blow dry them with a fan to prevent dust and impurities from settiıng on and distorting the plate emulsion. Overexposed and/or overdeveloped plates were salvaged by bleaching the density using Kodak farmers reducer. Plates that were underexposed and/or underdeveloped were salvaged by intensifying the density using Kodak chromium intensifier.

\section{$\underline{\text { Reconstruction }}$}

After developing the holograms, the next step was to reconstruct the interferograms. A typical reconstruction system is shown in Figure 11 The output beam of an argon-1on 200 milliwatt continuous wave laser at 5145 \& wavelength was expanded and collimated by a microscope objective lens and reflected at an angle duplicating the or iginal angle of the reference beam. This beam passed through the ambient and test condition holograms which were held in a plate holder.

The first step of the reconstruction process was to match the density of the test condition and ambient condition holograms It was found that the matched holograms of medium density gave the best quality interferograms during reconstruction This medium density range of 0.85 to 1.07 was measured on a Weston densitometer model 877 Light and dark density plates gave poorer quality interferograms, because of low contrast. The usable range of these paired density plates was limited by the ability to see a silhouette of the model (using an 8-x magnifier on the reconstruction camera ground glass). The second step of the reconstruction process was to place the test and ambient condition holograms in the plate holder in the same relative position as they were recorded in the wind tunnel with the emulsion side toward the incoming reference beam. The plate holder was slightly rotated in the vertical axis so that the reconstruction beam duplicated the approximate $20^{\circ}$ angle of the reference beam and the plates. At the correct angle, the brightest image of the flow was seen Micrometers on the plate holder were used to move one plate relative to the other to superimpose the silhouettes of the model on both plates. At this point, an 8-x magnifier was used on the camera's ground glass to observe fringes near the model and to check superimposition of the silhouettes. If the silhouettes were superimposed, a fringe pattern would be present

The final step was to adjust the plates and reconstruct to an infinite-fringe interferogram, i.e., fringes on an infinite-fringe interferogram are constant contours of index of refraction changes. For twodimensional flows, the fringes become constant density contours which make interpretation very easy. For most aerodynamic applications, the region several model diameters ahead of the model will be a region of unchanged or ambient refraction index. Using this region of uniform refractive index, the plates were adjusted slightly to get one or two broad fringes in that region. This technique was subjective and required some knowledge of the aerodynamics of the flow. When this was accomplished, an infinite-fringe interferogram was observed The image of the reconstruction was then taken with a $4 \times 5-1$ nch view camera. Figure 12 shows a typical reconstructed interferogram of an airfoll $10^{n}$ The fringes from the interferograms were digitized and reduced into density data This was originally done by manually counting the fringes, tracing them on a graphics table and connecting this data to a computer. Recently, to replace this laborious manual method, a semi-automatic fringe evaluation system was developed. ${ }^{11}$ This system uses an image-processing unit, De Anza 1P-6400, that was connected to a VAX 11/90 host computer.

\section{Conclusions}

The practical aspects of laser holographic interferometry, as presented here, proved to be highly effective in reducing or eliminating many problems associated with wind tunnel interferometer systems. The problems and their solutions are as follows. 
1 Vibration problems: solved by using reinforced mounts and enclosing the laser beam paths in cloth bellows

2 Alignment problems solved by using remotely controlled motorized actuators and polaroid test films

3 Holographic recording: solved by using plate identifier and/or duplicate test exposure techniques. (Several holograms are taken for each test condition)

4 Photographic processing solved by devising inspection development and dryıng techniques.

5 Reconstructing interferograms: solved by adding turning mirrors to facilitate double-plate adjustments and pairing of plate densities for improved interferogram recording techniques.

\section{References}

1 Spaid, F W and Bachalo, W D, Experiments in the Flow about a Supercritical Airfoil, Including Holographic Interferometry, AIAA Paper 80-0343, Pasadena, CA, 1980.

2 Lee, G., Buell, D A, Lıcursı, J P, and Craıg, J E, "Laser Holographı Interferometry for an Unsteady Airfoll Undergoing Dynamic Stall," AIAA J., Vol 22, No. 4, pp. 504-511, April 1984

3. Lee, G, A Tomographic Technique for Aerodynamics at Transonic Speeds, 11 th International Congress on Instrumentation in Aerospace Simulation Facilities, Stanford University, Palo Alto, CA, August $26-28,1985$.

4 Kittleson, J K. and Yu, Y., Reconstruction of a Holographic Interferogram Data, AIAA Paper 85-0370, January 1985 .

5 Vest, C M., Holographic Interferometry, John Wiley \& Sons, New York, 1979, pp $254-284$.

6 Craig, J. E, Lee, G., and Bachalo, W. D., Nd:Yag Holograph1c Interferometer for Aerodynamic Research, SPIE Paper 353-15, San Diego, CA, August 1982.

7 Bachalo, W. D, "Flow-Field Measurements on an Airfoll with an Oscillating Trailing-Edge Flap Using Holographic Interferometry, NASA CR-16604, July 1984.

8 Dunagan, J E, Brown, J L, and Miles, J. B., A Holographic Interferometer Study of an Axisymmetric Shock-Wave/Boundary-Layer Strong Interaction Flow, AIAA 18th Fluid Dynamics and Plasmadynamics and Lasers Conference, Cincinnati, Oh10, July 16-18, 1985.

9. Troiınger, J. D., "Laser Instrumentation for Flow Field Diagnostics," AGARDograph No. 186, 1977, p. 77

10 Johnson, D A and Bachalo, W D, Transonic Flow About a Two-Dimensional Airfoil-Inviscid and Turbulent Flow Properties, AIAA Paper 78-1117, 1978.

11 Becker, F. and Yu, Y. H., Application of Digital Interferogram Evaluation Technique to the Measurement of Three-Dimensional Flow Fields, Paper No. 85-0037, Presented at AIAA 23rd Aerospace Sciences Conference, Reno, Nevada, January 1985

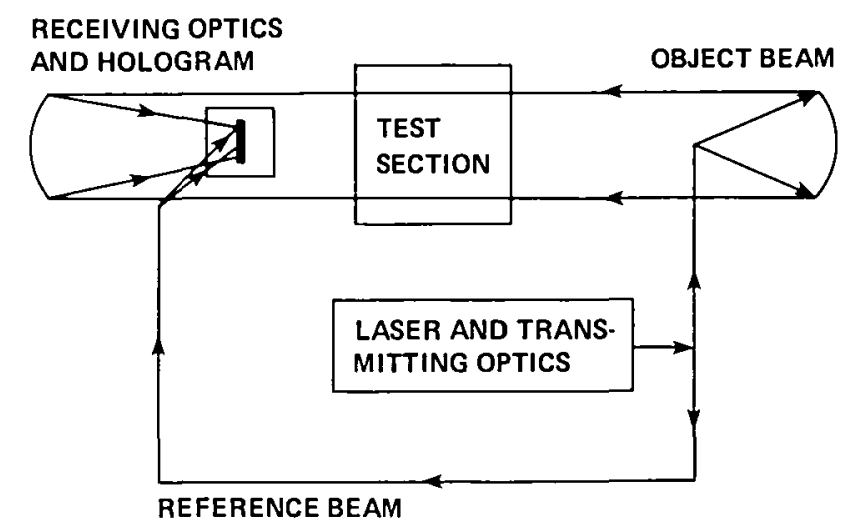

Figure 1 Typical of $f$-axis holographic interferometer 


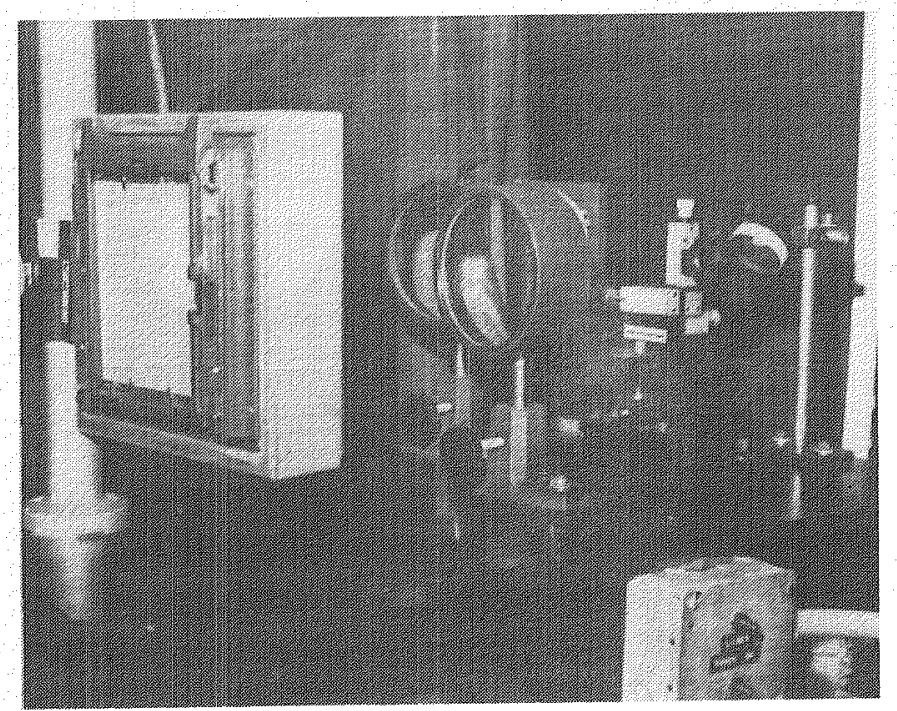

(a) RECEIVING OPTICS AND HOLOGRAM

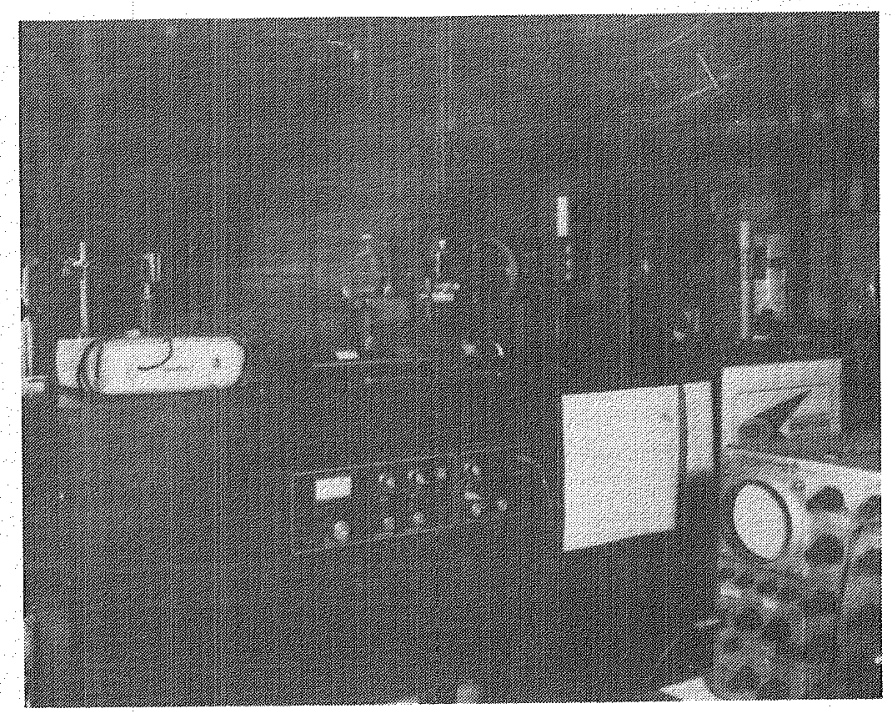

(b) LASER TRANSMITTING OPTICS

Figure 2. Interferometer system in the $2 \times 2$ Foot Transonic Wind Tunnel. 


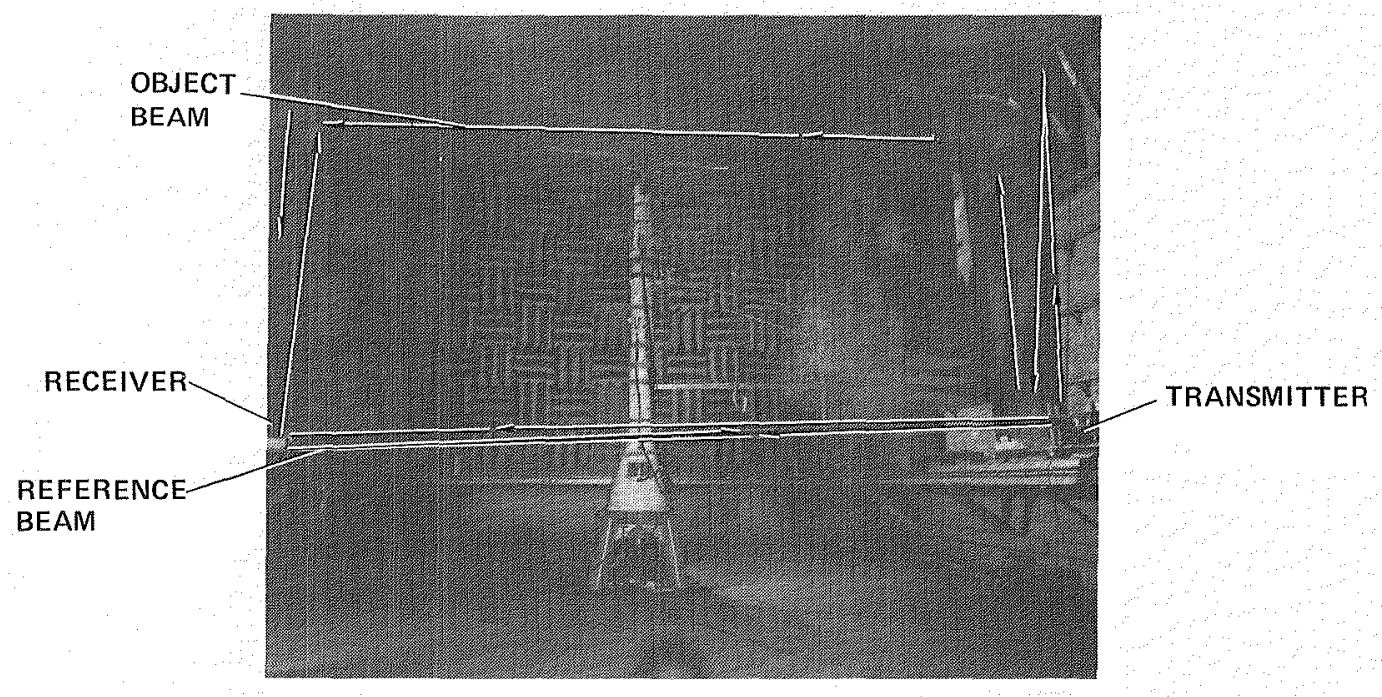

Figure 3. Interferometer in the Army Anechoic Test Chamber.

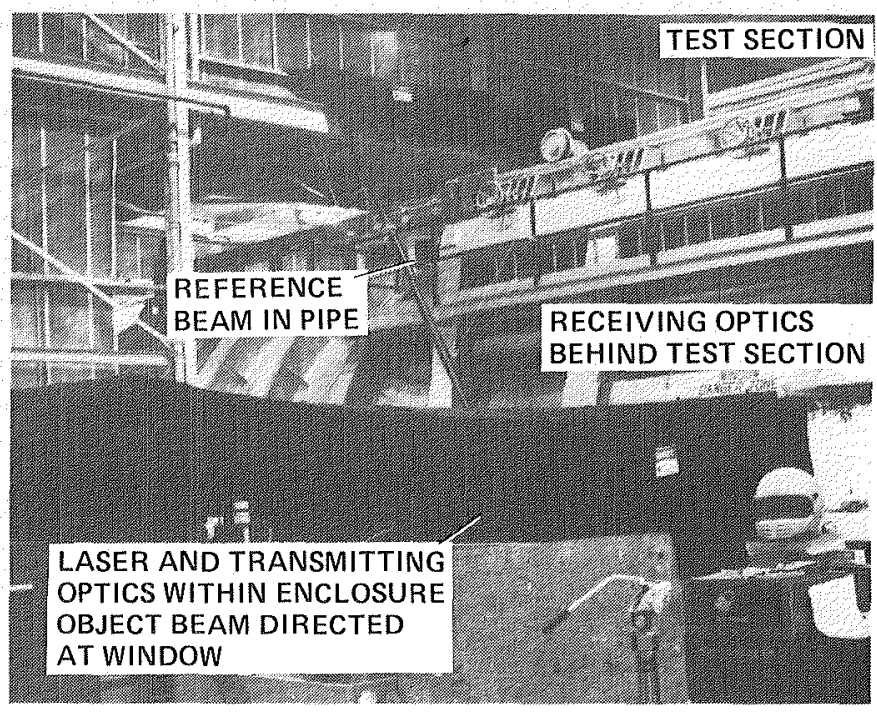

Eigure 4. NASA Ames 11-Foot Interferometer System. 


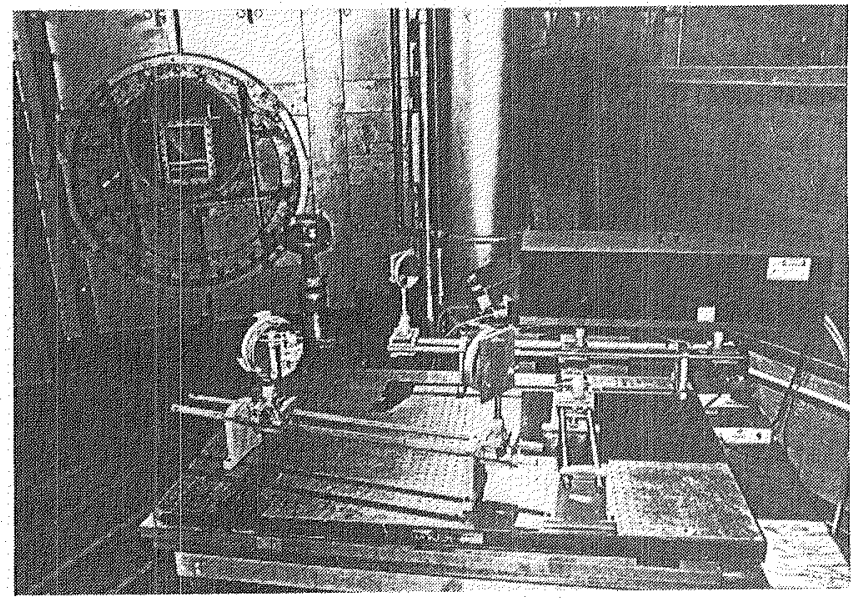

(a) TRANSMITTER

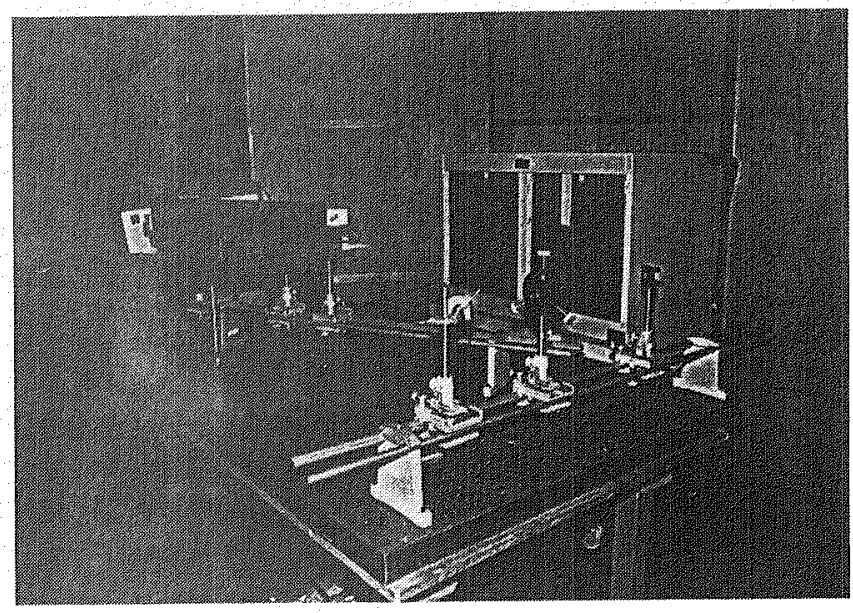

(b) RECEIVER

Figure $5.6 \times 6$ Foot Supersonic Interferometer system.

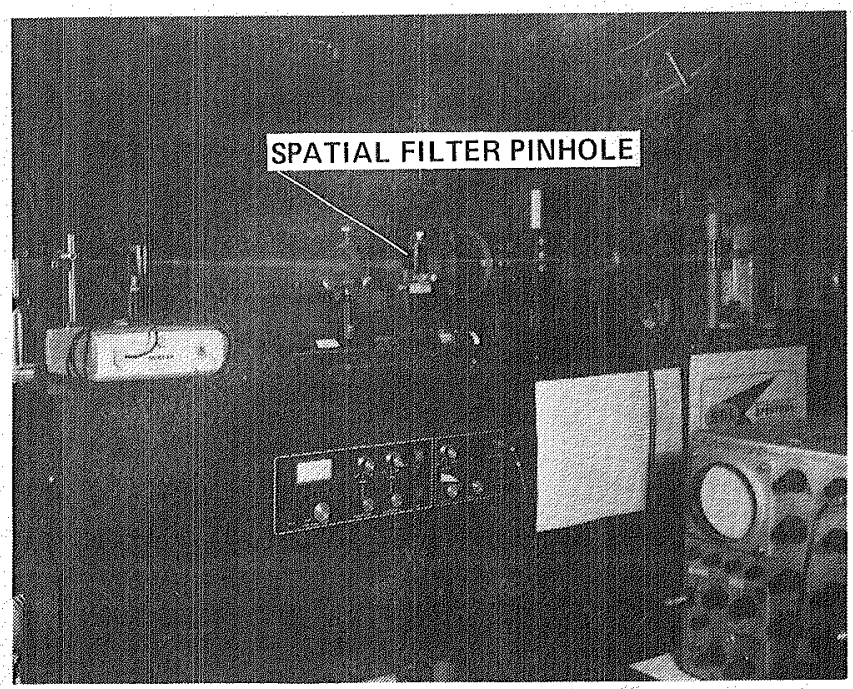

Figure $6.2 \times 2$ Foot Transonic Wind Tunnel interferometer system, showing location of spatial filter pinhole.

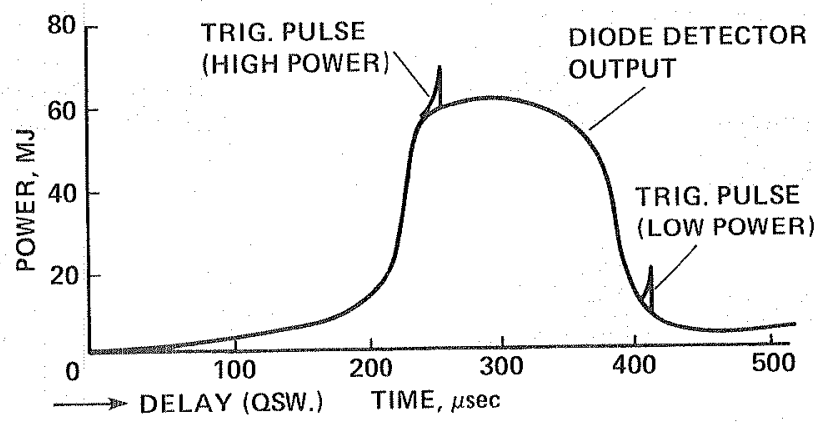

Figure 7. Laser flashlamp response curve. 


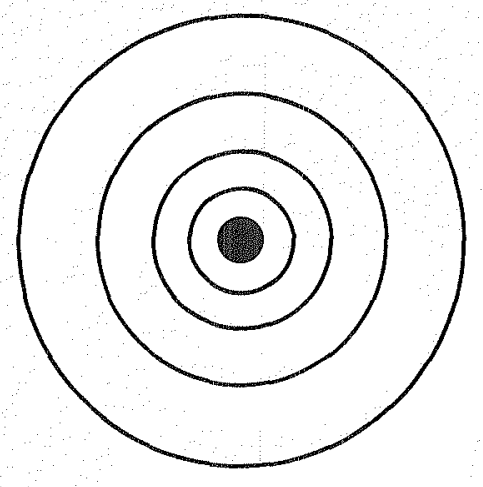

(a) GOOD PATTERN

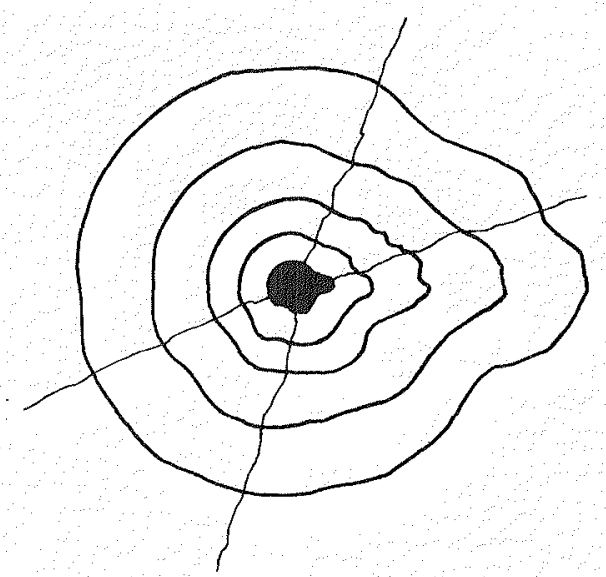

(b) BAD PATTERN

Figure 8. Spatial filter pinhole diffraction pattern.

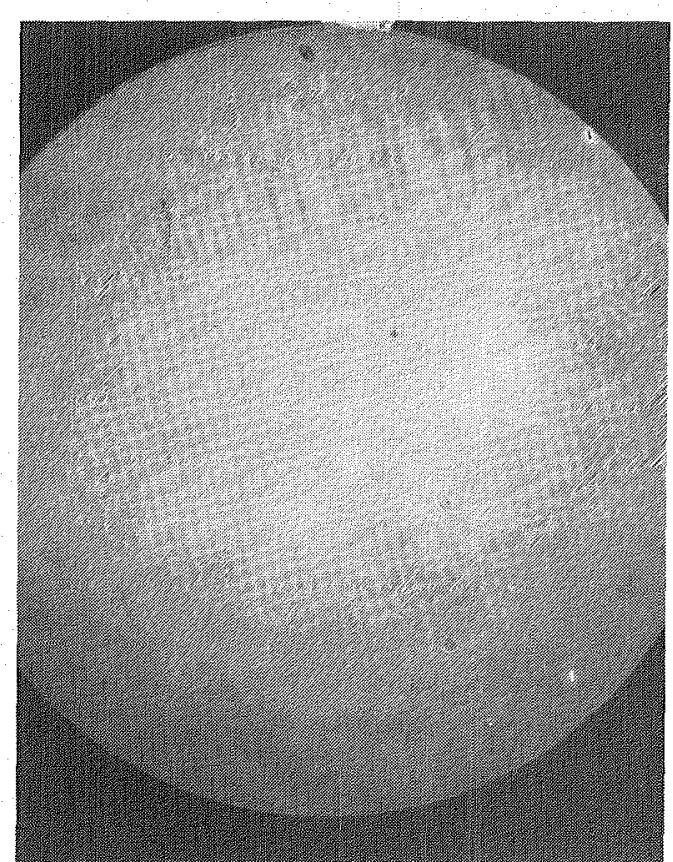

(a)

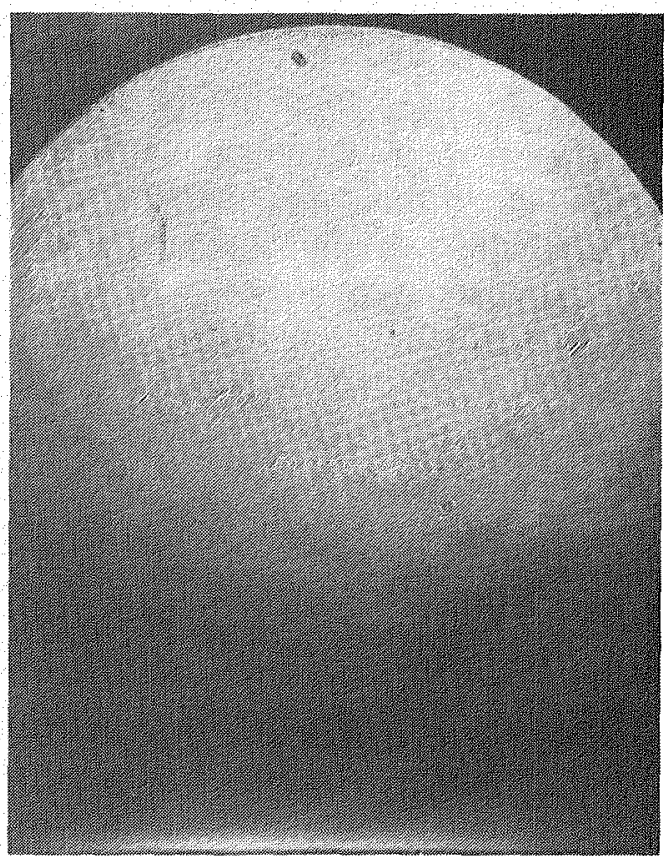

(b)

Figure 9. Polaroid test alignment pattern. a) Even exposure indicating correct laser beam alignment. b) Uneven exposure indicating incorrect laser beam alignment. 


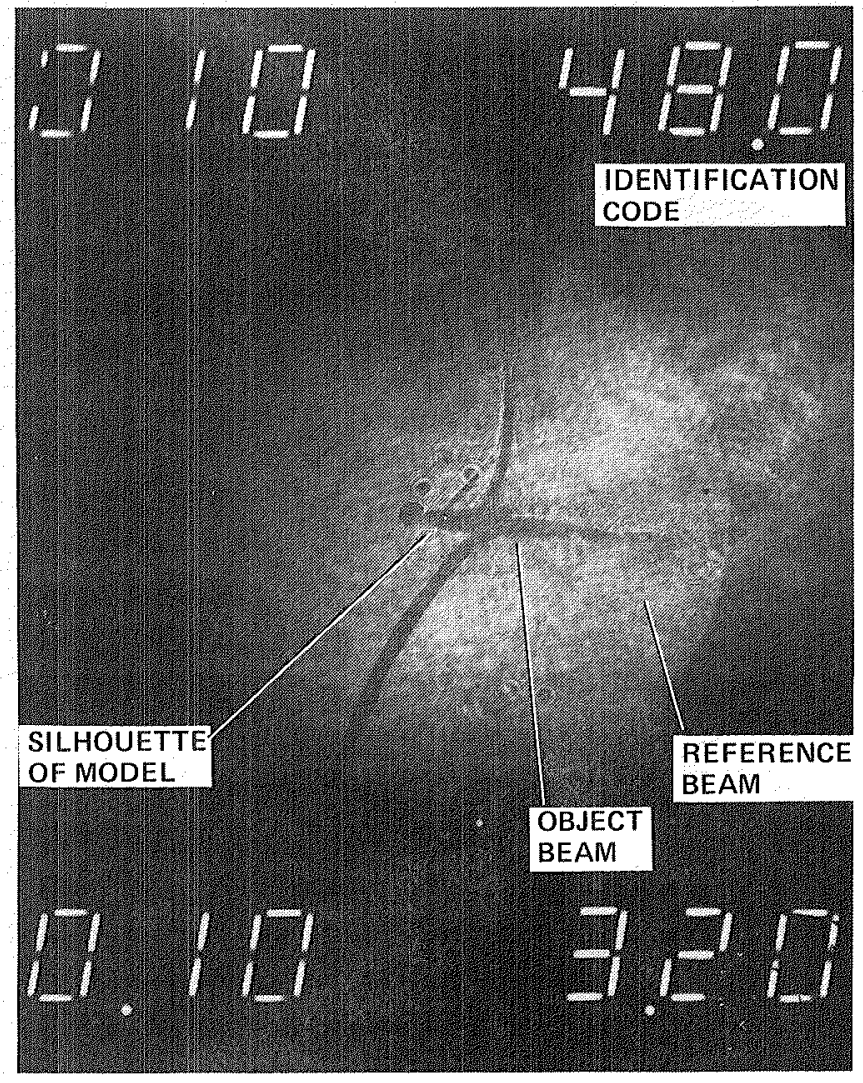

Figure 10. Holographic plate showing identification code.

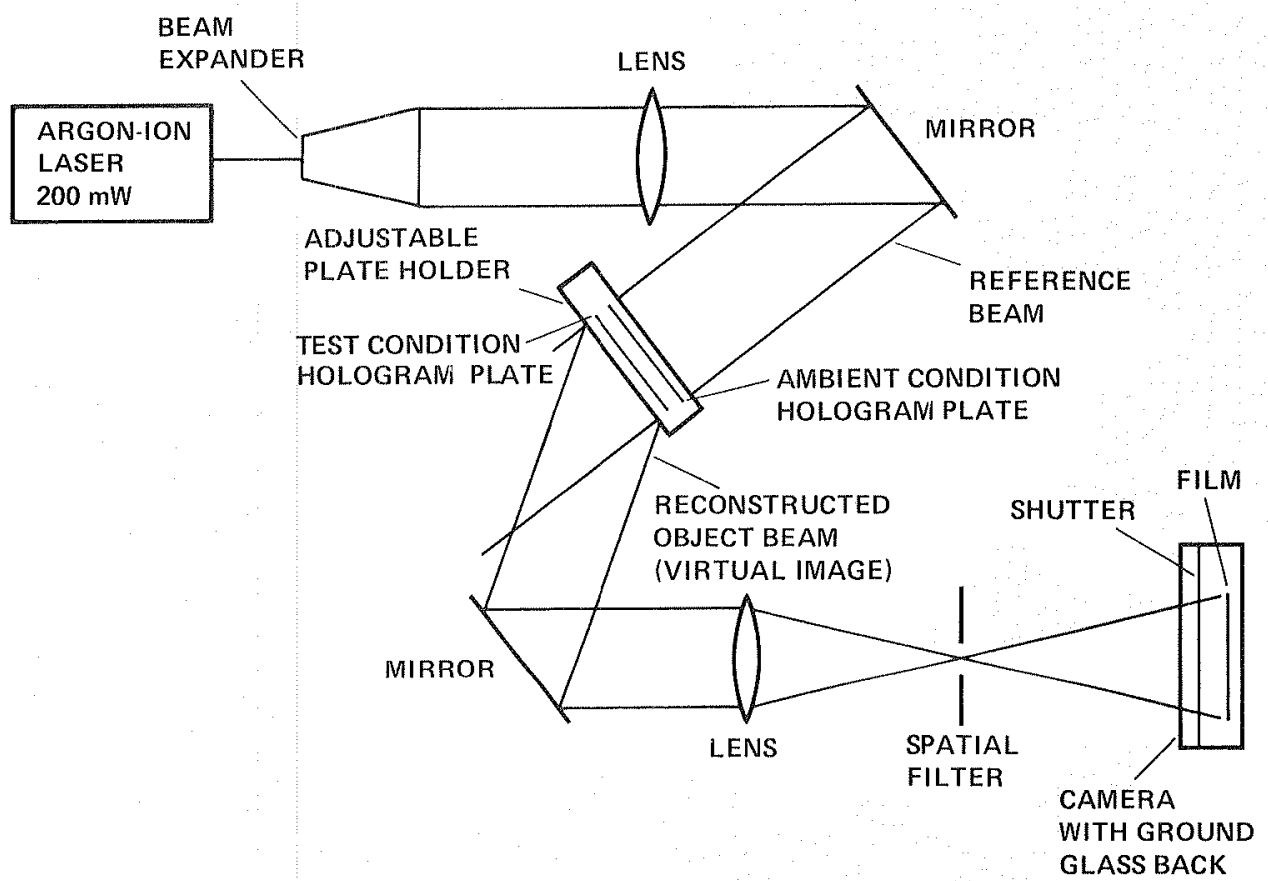

Figure 11. Holographic interferometer reconstruction system. 


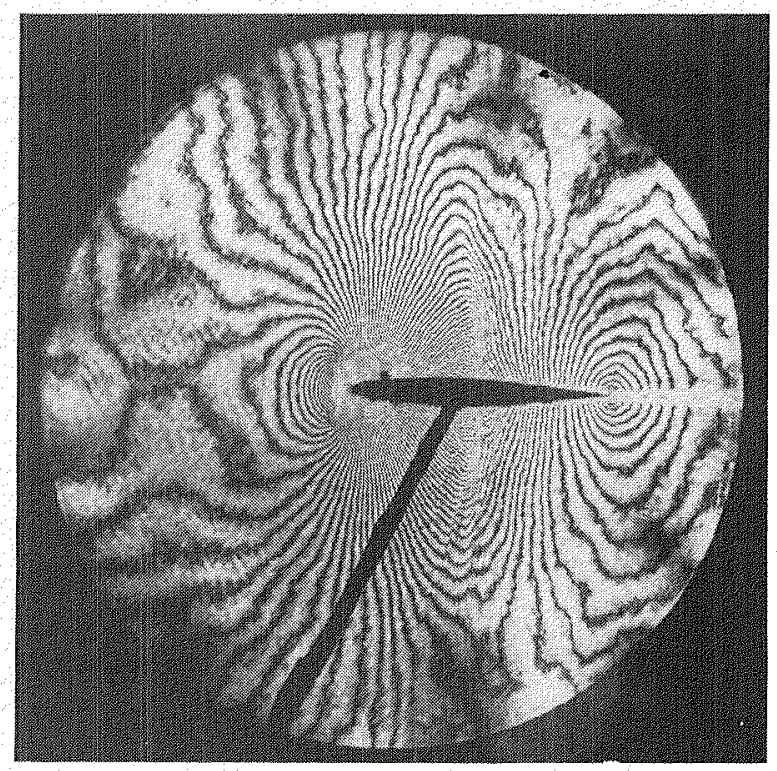

Figure 12. Typical infinite-fringe interferogram of the flow around a model airfoil. 


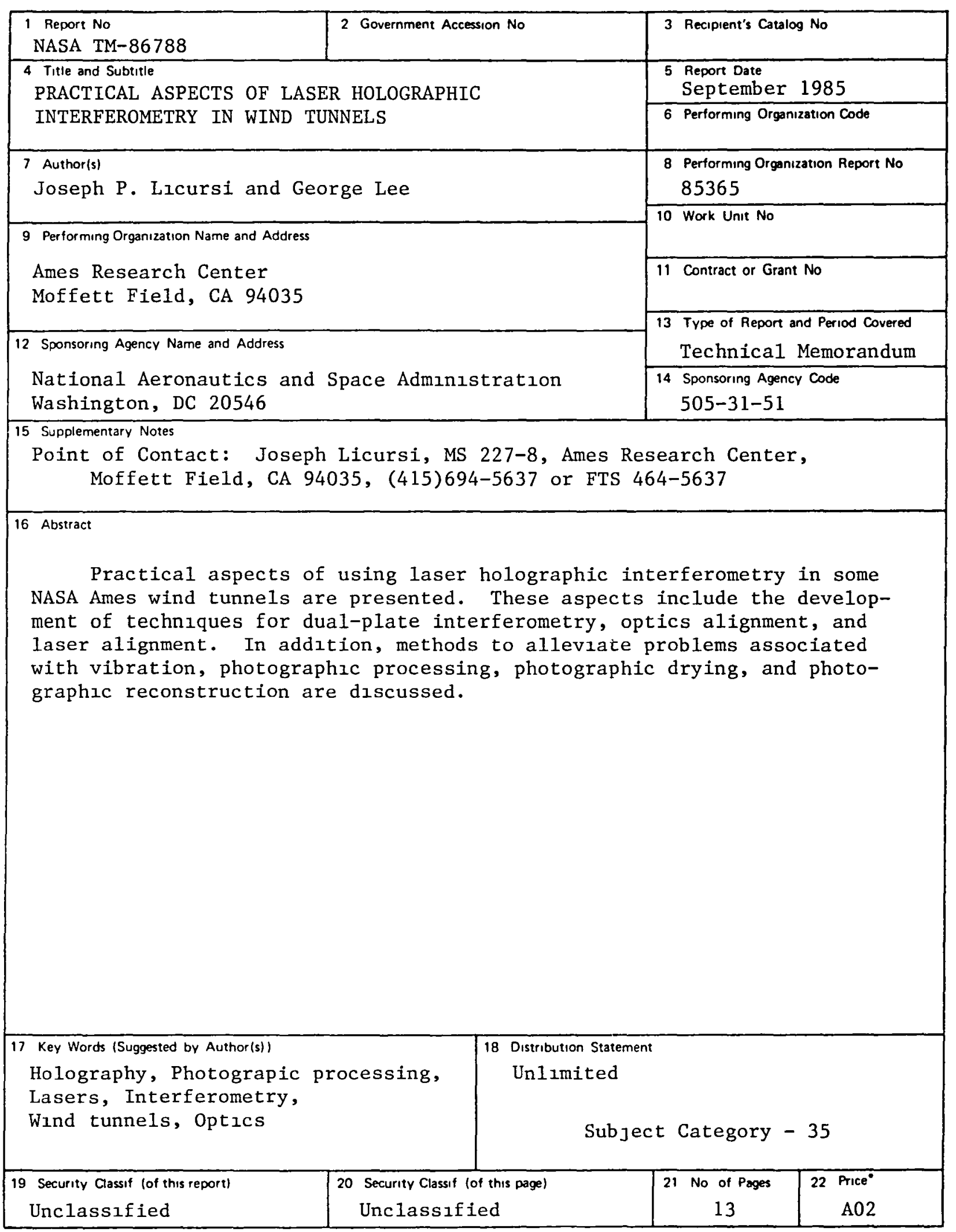




\section{End of Document}

